\title{
Качество корпоративного управления: коммерческие и исследовательские рейтинги
}

\author{
Шипилова А.O. ${ }^{28}$
}

Статья знакомит читателя с ключевыми рейтингами корпоративного управления, рассчитываемыли различными агентствами. Рассматриваются особенности $u$ методология таких рейтингов, преследуемые ими задачи, а также наличие таких рейтингов для российских компаний. Кроме того, внимание уделяется и рейтингам, сформировавшимся в академической среде. На основе анализа существующих рейтингов и исследований делается вывод о том, что научно обоснованный алгоритм построения корпоративного рейтинга еще не создан.

$J E L: G 24$

Ключевые слова: корпоративное управление, рейтинги, советы директоров

\section{Введение}

Рейтингование корпоративного управления начало бурно развиваться в начале 2000 -х годов. Толчком для его развития послужило резкое понижение уровня доверия инвесторов к компаниям, вызванное чередой раскрывшихся эпизодов мошенничества, таких как дело Enron или Worldcom. В качестве ответа на понижение общего уровня доверия к компаниям правительствами разных стран и бизнес-сообществом был принят ряд мер, направленных на усиление контроля за компаниями не связанных с ними сторон. Так, в 2002 году был подписан акт Sarbanes-Oxley, ужесточавший требования к корпоративному управлению и раскрытию информации публичными компаниями.

Создание рейтингов корпоративного управления также было призвано увеличить прозрачность деятельности компаний и существенно снизить риски рядовых инвесторов [Drake, 2002]. Кроме того, рейтингование корпоративного управления позволило компаниям сравнивать себя с конкурентами и совершенствовать существующие практики в этой области.

Публикуемые рейтинги качества корпоративного управления можно классифицировать по нескольким признакам:

1) по стране-источнику: рассчитываемые в России или за рубежом;

2) по исследовательскому фокусу: рейтинги собственно корпоративного управления и кредитные рейтинги, включающие показатели корпоративного управления, а также общие и узкоспециализированные рейтинги;

3) по охвату: рейтинги, рассчитываемые для одной или нескольких стран, охватывающие или не охватывающие растущие рынки;

4) по авторам: рейтинги, публикуемые агентствами или разрабатываемые отдельными исследователями.

Качество корпоративного управления традиционно оценивается по балльной шкале, которая часто дополняется категориями «+» или «-». В подавляющем большинстве случаев компании могут на добровольной основе раскрывать или не раскрывать присвоенные им рейтинги корпоративного управления.

${ }^{28}$ Стажер-исследователь научно-учебной Лаборатории корпоративных финансов ГУ ВШЭ. 


\section{Коммерческие рейтинги корпоративного управления}

Пожалуй, наиболее известными рейтингами корпоративного управления являются рейтинги компании Standard and Poor's. Критерии и методология первых рейтингов корпоративного управления Standard and Poor's были разработаны еще в 1998 году. Основными критериями являются качество защиты прав акционеров и других заинтересованных сторон, эффективность совета директоров, структура собственности и прозрачность деятельности компании. Для расчета своих рейтингов специалисты Standard and Poor's помимо общедоступной информации используют ряд других документов, предоставляемых компанией-клиентом: протоколы заседаний совета директоров, контракты с внешними аудиторами, внутренние регламенты по стратегическому планированию и тому подобные документы.

В 2007 году компания Standard and Poor's перешла от расчета Corporate Governance Score к новому рейтингу GAMMA. Большинство характеристик, принимаемых во внимание при расчете рейтинга, остались без изменения, однако важным шагом со стороны Standard and Poor's стало включение в рейтинг показателей качества риск-менеджмента и стратегического планирования. При этом в отношении стратегии уделяется внимание горизонту и детализации проработки стратегии, способности компании реагировать на изменения во внешней среде, четкости распределения ролей, а в отношении рискменеджмента - качеству внедренной системы управления рисками и ее влиянию на принятие решений.

Еще один рейтинг компании Standard and Poor's - Transparency and Disclosure рассчитывается на основе только публичной информации. Как и рейтинг корпоративного управления компании Audit Integrity, он фокусируется только на одной из составляющих качества корпоративного управления - на качестве раскрытия информации. При этом основное внимание уделяется раскрытию информации о фактах, наиболее важных для потенциальных инвесторов, - высокорисковых событиях, признанию выручки, оценке активов и обязательств.

Широко известны еще несколько рейтингов корпоративного управления, например рассчитываемые компаниями Institutional Shareholder Services или Governance Metrics International.

В таблице 1 обобщаются данные о наиболее известных зарубежных рейтингах корпоративного управления ${ }^{29}$.

${ }^{29}$ При составлении таблицы использовались сайты упоминаемых рейтинговых агентств, а также статьи Барретта и Дрейка [Barrett et al., 2004; Drake, 2002]. 
Таблица 1

Основные зарубежные рейтинги корпоративного управления

\begin{tabular}{|c|c|c|c|c|c|}
\hline $\begin{array}{l}\text { Название } \\
\text { рейтинга }\end{array}$ & Компания & $\begin{array}{l}\text { Период } \\
\text { расчета }\end{array}$ & $\begin{array}{c}\text { Доступность } \\
\text { для растущих } \\
\text { рынков } \\
\end{array}$ & $\begin{array}{c}\text { Условия } \\
\text { раскрытия }\end{array}$ & $\begin{array}{c}\text { Использованные } \\
\text { переменные }\end{array}$ \\
\hline \multirow{4}{*}{$\begin{array}{l}\text { CGS - } \\
\text { Corporate } \\
\text { Governance } \\
\text { Score }\end{array}$} & \multirow[t]{4}{*}{$\begin{array}{l}\text { Standard and } \\
\text { Poor's }\end{array}$} & \multirow[t]{4}{*}{$\begin{array}{l}2002- \\
2007\end{array}$} & \multirow[t]{4}{*}{ Доступен } & \multirow{4}{*}{$\begin{array}{l}\text { Для компаний, } \\
\text { оплачивающих } \\
\text { расчет рейтинга } \\
\text { или для всех, } \\
\text { если компании } \\
\text { выбирают } \\
\text { данную опцию }\end{array}$} & $\begin{array}{l}\text { Структура } \\
\text { собственности и ее } \\
\text { влияние }\end{array}$ \\
\hline & & & & & $\begin{array}{l}\text { Права групп с } \\
\text { финансовым } \\
\text { интересом в } \\
\text { деятельности } \\
\text { компании }\end{array}$ \\
\hline & & & & & \begin{tabular}{|l} 
Финансовая \\
прозрачность и \\
раскрытие \\
информации
\end{tabular} \\
\hline & & & & & $\begin{array}{l}\text { Структура и динамика } \\
\text { совета директоров }\end{array}$ \\
\hline \multirow{4}{*}{$\begin{array}{l}\text { GAMMA - } \\
\text { Governance, } \\
\text { Management, } \\
\text { Accountability } \\
\text { Metrics and } \\
\text { Analysis }\end{array}$} & \multirow[t]{4}{*}{$\begin{array}{l}\text { Standard and } \\
\text { Poor's }\end{array}$} & \multirow[t]{4}{*}{$\begin{array}{l}\text { С } 2007 \\
\text { года }\end{array}$} & \multirow[t]{4}{*}{ Доступен } & \multirow{4}{*}{$\begin{array}{l}\text { Для компаний, } \\
\text { оплачивающих } \\
\text { расчет рейтинга } \\
\text { или для всех, } \\
\text { если компании } \\
\text { выбирают } \\
\text { данную опцию }\end{array}$} & $\begin{array}{l}\text { Влияние структуры } \\
\text { собственности }\end{array}$ \\
\hline & & & & & Права акционеров \\
\hline & & & & & $\begin{array}{l}\text { Прозрачность, аудит, } \\
\text { риск-менеджмент на } \\
\text { предприятии } \\
\end{array}$ \\
\hline & & & & & $\begin{array}{l}\text { Эффективность совета } \\
\text { директоров, } \\
\text { стратегия, политика } \\
\text { выплаты } \\
\text { вознаграждений } \\
\end{array}$ \\
\hline $\begin{array}{l}\text { Transparency } \\
\text { and disclosure } \\
\text { (T\&D) Rating }\end{array}$ & $\begin{array}{l}\text { Standard and } \\
\text { Poor's }\end{array}$ & $\begin{array}{l}\text { С } 2001 \\
\text { года }\end{array}$ & Доступен & Для всех & $\begin{array}{l}\text { Качество раскрытия } \\
\text { информации }\end{array}$ \\
\hline \multirow{3}{*}{$\begin{array}{l}\text { AGR } ®-\text { The } \\
\text { Audit Integrity } \\
\text { Accounting } \\
\text { and } \\
\text { Governance } \\
\text { Risk rating }\end{array}$} & \multirow[t]{3}{*}{$\begin{array}{l}\text { Audit } \\
\text { Integrity, Inc. }\end{array}$} & \multirow[t]{3}{*}{$\begin{array}{l}\text { С } 1999 \\
\text { года }\end{array}$} & \multirow[t]{3}{*}{$\begin{array}{l}\text { Недоступен } \\
\text { (только США) }\end{array}$} & \multirow[t]{3}{*}{ Для всех } & $\begin{array}{l}\text { Корпоративное } \\
\text { управление }\end{array}$ \\
\hline & & & & & \begin{tabular}{|l|} 
Высокорисковые \\
события
\end{tabular} \\
\hline & & & & & $\begin{array}{l}\text { Оценка активов и } \\
\text { обязательств }\end{array}$ \\
\hline \multirow{3}{*}{$\begin{array}{l}\text { Board } \\
\text { Effectiveness } \\
\text { Rating - часть } \\
\text { системы } \\
\text { Board } \\
\text { Analyst }{ }^{\circledR}\end{array}$} & \multirow[t]{3}{*}{$\begin{array}{l}\text { The Corporate } \\
\text { Library }\end{array}$} & \multirow[t]{3}{*}{$\begin{array}{l}\text { С } 1999 \\
\text { года }\end{array}$} & \multirow[t]{3}{*}{ Недоступен } & \multirow[t]{3}{*}{\begin{tabular}{|l} 
Для \\
покупателей \\
услуги
\end{tabular}} & $\begin{array}{l}\text { Состав совета } \\
\text { директоров и порядок } \\
\text { его формирования } \\
\end{array}$ \\
\hline & & & & & $\begin{array}{l}\text { Политика выплат } \\
\text { вознаграждений топ- } \\
\text { менеджменту }\end{array}$ \\
\hline & & & & & \begin{tabular}{|l|} 
Меры защиты от \\
поглощения \\
Подотчетность совета \\
директоров
\end{tabular} \\
\hline
\end{tabular}




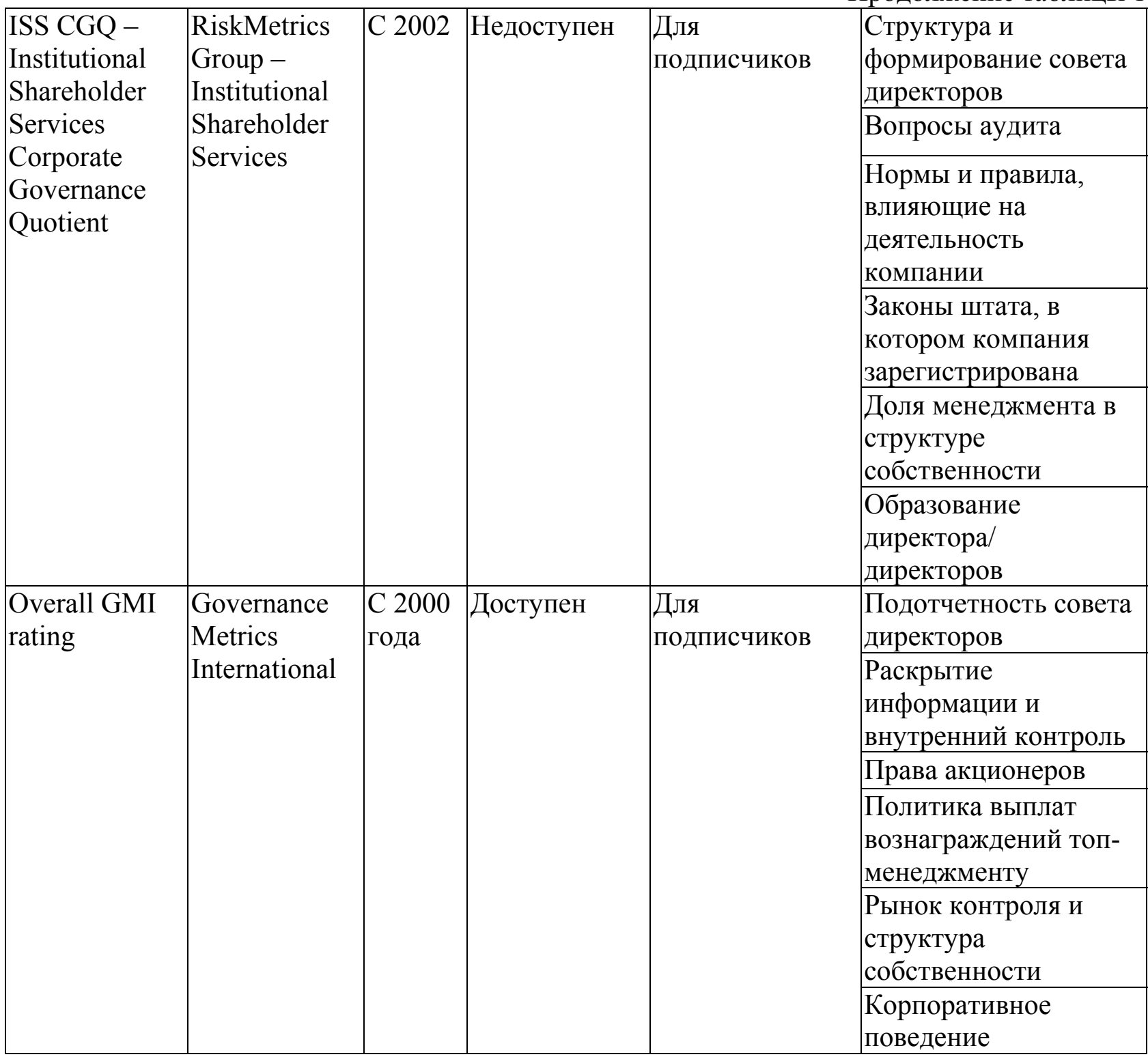

В таблице 2 систематизирована методология расчета существующих рейтингов корпоративного управления

Таблица 2

Методология коммерческих рейтингов корпоративного управления

\begin{tabular}{|l|l|l|l|l|l|l|l|}
\hline \multirow{2}{*}{$\begin{array}{l}\text { Учет } \\
\text { особенностей }\end{array}$} & \multicolumn{6}{|c|}{ Рейтинг } \\
\cline { 2 - 8 } & Совета & GAMMA & T\&D & AGR & BER & ISS CGQ & GMI \\
\hline $\begin{array}{l}\text { директоров } \\
\text { Структуры } \\
\text { собственности }\end{array}$ & $\mathrm{X}$ & $\mathrm{X}$ & $\mathrm{X}$ & & $\mathrm{X}$ & $\mathrm{X}$ & $\mathrm{X}$ \\
\hline $\begin{array}{l}\text { Прав } \\
\text { акционеров }\end{array}$ & $\mathrm{X}$ & $\mathrm{X}$ & & & & & $\mathrm{X}$ \\
\hline $\begin{array}{l}\text { Раскрытия } \\
\text { информации }\end{array}$ & $\mathrm{X}$ & $\mathrm{X}$ & $\mathrm{X}$ & $\mathrm{X}$ & & $\mathrm{X}$ & $\mathrm{X}$ \\
\hline
\end{tabular}

Как видно из таблиц, в большинстве рейтингов так или иначе затронуты все основные вопросы, связанные с корпоративным управлением: характеристики совета директоров, структура собственности, защита прав акционеров, качество раскрытия информации. 
Рейтинги T\&D и AGR, a также рейтинг эффективности совета директоров (Board Effectiveness), более специализированы.

Компании Moody's Investors Service и Fitch не выпускают рейтингов, посвященных исключительно корпоративному управлению. Эти рейтинговые агентства используют показатели качества корпоративного управления как составную часть своих кредитных рейтингов. При этом информация о корпоративном управлении клиента может оказать значимое влияние на его кредитный рейтинг. В России на данный момент рейтинги корпоративного управления систематически рассчитывает только Консорциумом Рейтингового агентства “Эксперт РА”» и Российского института директоров (проект «Национальный рейтинг корпоративного управления»). Основой для расчета рейтинга является публичная информация, а также информация из специальной рейтинговой анкеты, заполняемой и заверяемой представителями самой компании. НРКУ рассчитывается с учетом таких компонентов, как защита прав акционеров, состав и эффективность работы органов управления и контроля, раскрытие информации, корпоративная социальная ответственность (см. табл. 3).

Таблица 3

Компоненты «Национального рейтинга корпоративного управления» РИД

\begin{tabular}{|c|c|c|c|}
\hline Права акцчионеров & $\begin{array}{l}\text { Деятельность органов } \\
\text { управления и контроля }\end{array}$ & $\begin{array}{l}\text { Раскрытие } \\
\text { информации }\end{array}$ & $\begin{array}{l}\text { Корпоративная } \\
\text { социальная } \\
\text { ответственность } \\
\end{array}$ \\
\hline Права собственности & Совет директоров & $\begin{array}{l}\text { Уровень раскрытия } \\
\text { нефинансовой } \\
\text { информации }\end{array}$ & $\begin{array}{l}\text { Наличие } \\
\text { документа, } \\
\text { закрепляющего } \\
\text { КСО } \\
\end{array}$ \\
\hline $\begin{array}{l}\text { Право на участие в } \\
\text { управлении }\end{array}$ & Исполнительные органы & $\begin{array}{l}\text { Уровень раскрытия } \\
\text { финансовой } \\
\text { информации }\end{array}$ & $\begin{array}{l}\text { Наличие } \\
\text { этического } \\
\text { кодекса }\end{array}$ \\
\hline $\begin{array}{l}\text { Право на получение } \\
\text { дивидендов }\end{array}$ & $\begin{array}{l}\text { Контроль за финансово- } \\
\text { хозяйственной } \\
\text { деятельностью }\end{array}$ & $\begin{array}{l}\text { Общая дисциплина } \\
\text { раскрытия } \\
\text { информации }\end{array}$ & $\begin{array}{l}\text { КСО в отношении } \\
\text { сотрудников }\end{array}$ \\
\hline $\begin{array}{l}\text { Риски нарушения } \\
\text { прав }\end{array}$ & $\begin{array}{l}\text { Взаимодействие между } \\
\text { органами управления }\end{array}$ & $\begin{array}{l}\text { Равнодоступность } \\
\text { информации }\end{array}$ & $\begin{array}{l}\text { КСО в отношении } \\
\text { населения }\end{array}$ \\
\hline \multirow{3}{*}{$\begin{array}{l}\text { Дополнительные } \\
\text { обязательства } \\
\text { защите прав }\end{array}$} & & $\begin{array}{l}\text { КСО в отношении } \\
\text { природы }\end{array}$ \\
\hline & & & $\begin{array}{l}\text { КСО в отношении } \\
\text { конкурентов }\end{array}$ \\
\hline & & & $\begin{array}{l}\text { Подготовка } \\
\text { социальной } \\
\text { отчетности }\end{array}$ \\
\hline
\end{tabular}

Включение в расчет рейтинга показателя, характеризующего учет интересов общества, безусловно, является важным достоинством рейтинга, так как соответствует самому современному пониманию создания стоимости в рамках компании - стейкхолдерской концепции стоимости. Необходимо отметить, что Консорциум применяет единую методику для всех компаний вне зависимости от их структуры собственности. При расчете рейтинговой оценки наибольший вес имеют компоненты «Деятельность органов управления и контроля», а также «Раскрытие информации».

Институт корпоративного права и управления в 2001-2003 годах выпускал собственный рейтинг корпоративного управления, включавший такие традиционные показатели, как основные права акционеров, структура совета директоров, раскрытие 
информации и структура капитала. Интересной особенностью рейтинга было то, что он публиковался ежеквартально, независимо от согласия рейтингуемой компании. К сожалению, обновления для рейтингов не выпускались с IV квартала 2003 года.

\section{Исследовательские рейтинги корпоративного управления}

В результате мирового финансового кризиса рейтинги корпоративного управления, как и многие традиционные инструменты оценки рискованности компаний, подверглись жесткой критике. Многие задавались вопросом, точны ли существующие инструменты оценивания качества корпоративного управления и можно ли с их помощью прогнозировать будущие финансовые показатели компаний.

Уже в 2004 году Ларкер и др. [Larcker et al., 2004] показали, что даже при использовании большого числа интуитивно важных показателей удается объяснить только от 1 до $10 \%$ дисперсии показателей менеджерских решений и корпоративной эффективности. В статье Коэн, Уэнг [Koehn, Ueng, 2005] оценивается предсказательная сила рейтингов ISS и GMI. Тестируется в том числе гипотеза о том, что прибыль компаний с рейтингами выше среднего более высокого качества, чем прибыль компаний с рейтингами ниже среднего. В качестве оценки эффективности компании используется рейтинг «качества прибыли» компании Audit Integrity. T-test для разных моделей показывает, что разница между финансовыми результатами «хороших» и «плохих» компаний незначима при любом стандартном уровне значимости, то есть гипотеза отвергается. Мета-анализ, проведенный авторами, также показывает, что, возможно, существующие рейтинги корпоративного управления учитывают много избыточной информации. В исследовании Узун и др. [Uzun et al., 2004] только фактор присутствия независимых директоров в совете оказался значимым в регрессии, объясняющей вероятность участия компании в мошенничестве. Агравал и др. [Agrawal, Knoeber, 1996] и Хермалин и др. [Hermalin, Weisbach, 1991] не обнаружили значимой корреляции между составом совета директоров и прибылью компании. Итак, авторы делают вывод о том, что проверенные ими рейтинги корпоративного управления недостаточно эффективны, и рекомендуют для получения более полной картины использовать несколько рейтингов корпоративного управления одновременно. В то же время Браун и Мачин [Brown и Muchin, 2005], утверждают, что именно расхождения между разными рейтингами корпоративного управления приводят к падению доверия к каждому из них.

Несмотря на описанные выше претензии к существующим рейтингам корпоративного управления, речь идет не о полном отказе от рейтингования корпоративного управления, а об усовершенствовании существующих рейтингов. В связи с этим отдельным направлением научной работы на данный момент является конструирование исследователями новых рейтингов корпоративного управления (см. табл. 4).

Дробетц и др. [Drobetz et al., 2004] разработали рейтинг корпоративного управления для немецких компаний. При этом они исходили из того, что значения этого рейтинга при подстановке в модель САРМ и статическую модель Гордона должны объяснять среднегеометрическое значение доходности по акциям компаний за период с 1998-го по 2002 год. На основе немецкого Кодекса корпоративного управления авторами было отобрано 30 переменных, которые могли бы быть включены в рейтинг. Эти переменные делятся на пять категорий: следование определенной политике корпоративного управления, права акционеров, аудит, прозрачность и особенности менеджмента и совета директоров. Детальный вопросник по каждой из отобранных переменных был разослан во все компании, входящие в основные немецкие индексы. Очки, набранные ответившими фирмами по каждому пункту, суммировались. Авторы отмечают, что данный рейтинг позитивно коррелирован со стоимостью компаний и негативно - с ожидаемой доходностью по их акциям из-за ожиданий более низкого риска. 
Спанос и др. [Spanos et al., 2004] при конструировании рейтинга для греческих компаний также опирались на правовую базу страны, а именно на греческий добровольный кодекс корпоративного управления. На основе его глав был создан опросник из 54 пунктов. Ответы на 32 вопроса включались в рейтинг напрямую, 16 вопросов, объединенных в подгруппы, давали информацию только о пяти индикаторах, а шесть вопросов были контрольными. Наибольший вес на основе экспертных оценок авторского коллектива получили показатели прозрачности и раскрытия информации, вторыми по значимости были признаны права акционеров, затем особенности совета директоров и менеджмента и наконец корпоративная социальная ответственность. Авторы не исследовали взаимосвязи между полученным рейтингом и финансовыми показателями, ограничившись его построением.

Гомперс и др. [Gompers et al., 2003] сформировали методологию расчета своего рейтинга G-score на основе 24 показателей, предоставляемых организацией Investor Responsibility Research Center. Bce это меры защиты против поглощений, увеличивающие власть менеджеров, такие, как золотые или серебряные парашюты, выходные пособия, «отравленные пилюли», необходимость переизбрания совета директоров по частям, невозможность кумулятивного или тайного голосования. За использование каждого инструмента, ограничивающего права акционеров, к рейтингу компании прибавлялось по одному баллу. Минимально возможное значение рейтинга 0, максимально возможное - 24 . Стоит отметить, в результате «лучшему» корпоративному управлению соответствует меньшее значение G-score.

Таблица 4

Исследовательские рейтинги корпоративного управления

\begin{tabular}{|c|c|c|c|}
\hline \multirow{2}{*}{$\begin{array}{c}\text { Учет наличия и } \\
\text { особенностей }\end{array}$} & \multicolumn{3}{|c|}{ Рейтинг } \\
\hline & $\begin{array}{c}\text { Drobetz et al., } \\
2003\end{array}$ & $\begin{array}{c}\text { Spanos et al., } \\
2004\end{array}$ & $\begin{array}{l}\text { Gompers et } \\
\text { al., } 2003\end{array}$ \\
\hline $\begin{array}{l}\text { приверженности политике } \\
\text { корпоративного } \\
\text { управления }\end{array}$ & $\mathrm{X}$ & $\mathrm{X}$ & \\
\hline совета директоров & $\mathrm{X}$ & $\mathrm{X}$ & \\
\hline власти менеджеров & & $\bar{X}$ & $\bar{X}$ \\
\hline прав акционеров & $\mathrm{X}$ & $\mathrm{X}$ & $\mathrm{X}$ \\
\hline раскрытия информации & $\mathrm{X}$ & $\mathrm{X}$ & \\
\hline социальной политики & & $\mathrm{X}$ & \\
\hline
\end{tabular}

Рейтинги, разрабатываемые учеными, призваны исправить недостатки существующих коммерческих рейтингов на основе эконометрического анализа факторов корпоративного управления. Однако исследователям не всегда удается достигнуть этой цели. Так, Браун и Кейлор [Brown, Caylor, 2004] в результате сравнительного анализа рейтинга Gov-Score, публикуемого Institutional Shareholders Services, и G-Score [Gompers et al, 2003], пришли к выводу о большей прогнозной силе рейтинга ISS. 


\section{Заключение}

На данный момент как коммерческими организациями, так и группами ученых рассчитывается множество рейтингов корпоративного управления, способствующих принятию обоснованных индивидуальных инвестиционных решений и совершенствованию существующих практик корпоративного управления. В результате анализа литературы можно заключить, что научно обоснованный алгоритм построения корпоративного рейтинга еще не создан. Имеющиеся рейтинги основываются на интуиции и экспертных оценках их авторов, а также на действующем законодательстве. Если такой алгоритм создать все же удастся, то это станет прорывом в области корпоративных финансов и менеджмента.

\section{Список литературы}

1. Институт корпоративного права и управления [Электронный ресурc]. URL: http://www.iclg.ru (дата обращения: 09.03.2010).

2. Вербицкий, В., Горобцов, С. Национальный рейтинг корпоративного управления // Управление компанией (ЖУК). 2005. Т. 4, № 47. С. 63-66.

3. Национальный рейтинг [Электронный ресурс] // Российский институт директоров. URL: http://www.rid.ru/rating (дата обращения: 09.06.2010).

4. Рейтинги. Обзоры. Исследования. Конференции - Эксперт РА [Электронный ресурс]. URL: http://www.raexpert.ru (дата обращения: 09.03.2010).

5. Agrawal, A., Knoeber, C. R. (1996), Firm performance and mechanisms in control agency problems between managers and shareholders, Journal of Financial and Quantitative Analysis 31(3) (1996) 377-397.

6. Audit Integrity - Ноте [Электронный ресурc]. URL: http://www.auditintegrity.com (дата обращения: 09.03.2010).

7. Barrett, A., Todd, P., Shlaudecker, C. Corporate governance ratings [Электронный ресурс] // Corporate governance San Diego - Corporate directors forum. 2004. URL: http://www.directorsforum.com/resources/related_articles/corp_gov_ratings3-05.pdf (дата обращения: 14.07.2010).

8. Board Analyst

[Электронный ресурс].

URL: http://www.boardanalyst.com/index.asp?p=login (дата обращения: 09.03.2010).

9. Brown, L. D., Caylor, M. L. (2004), Corporate governance and firm performance [Электронный pecypc] // Social Science Research Network. URL: http://papers.ssrn.com/sol3/papers.cfm?abstract_id=586423\#_ (дата обращения: 14.07.2010).

10. Drake, D. S. (2002), Are you ready for the ratings game? The corporate governance rating phenomenon [Электронный ресурс] // Georgeson, a world leader in proxy solicitation. 2002. URL: http://www.georgeson.com/usa/download/articles/ratingsgame.pdf (дата обращения: 09.03.2010).

11. Drobetz, W., Schillhofer, A., and Zimmermann, H. (2003), Ein Corporate Governance Rating für deutsche Publikumsgesellschaften, Zeitschrift für Betriebswirtschaft, 74 (1) (2003) $1-21$.

12. Drobetz, W., Schillhofer, A., and Zimmermann, H. (2004), Corporate governance and expected stock returns: Evidence from Germany, European Financial Management 10 (2) (2004) 267-293.

13. Fitch Ratings [Электронный pecypc]. URL: http://www.fitchratings.ru (дата обращения: 09.03.2010).

14. GovernanceMetrics International [Электронный pecypc]. URL: http://www.gmiratings.com (дата обращения: 09.03.2010).

15. Gompers P., Ishii J., and Metrick A. (2003), Corporate governance and equity prices, Quarterly Journal of Economics, 118 (2003) 107-155. 
16. Hermalin, E. B., Weisbach, S. M. (1998), Endogenously chosen boards of directors and their monitoring of the CEO, The American Economic Review 88(1) (1998) 96-118.

17. Koehn, D., Ueng, J. (2005), Evaluating the evaluators: should investors trust corporate governance metrics ratings? Journal of Management and Governance, 9 (2005) 111-128.

18. La Porta, R., Lopez-de-Silanes, F., Shleifer, A. and Vishny, R. (1997), Legal determinants of external finance, Journal of Finance, 52 (3) (1997) 1131-1150.

19. Larcker, D. F., Scott, A. R., and Tuna, I. (2004), How Important is Corporate Governance? [Электронный pecypc] // Social Science Research Network. URL: http://papers.ssrn.com/sol3/papers.cfm?abstract_id=595821 (дата обращения: 14.07.2010).

20. Martynova, M., Renneboog, L. (2009), Corporate governance index: convergence and diversity of national corporate governance regulations. [Электронный pecypc] // Social Science Nesearch Network. URL: http://papers.ssrn.com/sol3/papers.cfm?abstract_id=1557627 (дата обращения: 14.07.2010).

21. Moody's - credit ratings, research tools and analysis for the global capital market. [Электронный ресурc]. URL: http://v3.moodys.com/Pages/default.aspx (дата обращения: 09.03.2010).

22. RiskMetrics Group [Электронный pecypc]. URL: http://www.riskmetrics.com (дата обращения: 09.03.2010).

23. Spanos, L., Tsipouri, L., Xanthakis, M. (2004). The construction of a corporate governance rating system for a small open capital market: Methodology and applications in the Greek market [Электронный pecypc] // Social Science Research Network: сайт. URL: http://ssrn.com/abstract=667623 (дата обращения: 14.07.2010).

24. Standard and Poor's - United States [Электронный pecypc]. URL: http://www.standardandpoors.com (дата обращения: 09.03.2010).

25. Standard and Poor's. Equity Research. GAMMA [Электронный pecypc]. URL: http://www.governance.standardandpoors.com (дата обращения: 09.03.2010).

26. Uzun, H., Szewczyk, S., and Varma, R. (2004), Board composition and corporate fraud, Financial Analysts Journal 60(3) (2004) 33-43. 